\title{
Influence of bitumen fractional composition on the physical and mechanical properties of cationic emulsion
}

\author{
Viktar Salauyeu $^{\mathrm{a}}$, Miglè Paliukaitè ${ }^{\mathrm{b}}$, María José Romero Moruno ${ }^{\mathrm{c}}$ \\ ${ }^{a}$ Belorussian Road Research Institute, 4th Zagorodny Lane 60, 220073 Minsk, Belarus \\ ${ }^{b}$ Road Research Institute, Vilnius Gediminas Technical University, Linkmenu st. 28, 08217-LT Vilnius, Lithuania \\ ${ }^{c}$ Universitat Politècnica de València (UPV), Camino de Vera, s/n, 46022 Valencia, Spain
}

\begin{abstract}
The primary objective of this paper was to investigate the impact of bitumen fractional composition on the physical-mechanical properties of cationic bitumen emulsion. The paper focuses on one kind of bitumen produced by oxidation process and special compounded bitumen produced by different oxidized components with various degrees of oxidation. The aim of this article is to determine how different structural types of bitumen (Sol, Gel and Sol-Gel) and the Colloidal Instability Index $\left(I_{\mathrm{c}}\right)$ influence the rheological properties of cationic bitumen emulsion. Bitumen fractional composition was determined by Iatroscan MK-6s chromatography. Moreover, it is established that using bitumen emulsions with compounded bitumen, the maximal speed of formation of a road surfacing from cold emulsion mixtures is reached. The results of practical application of bitumen emulsions with compounded bitumen for Slurry seal in road building in Belarus are presented.
\end{abstract}

Keywords: bitumen emulsion; fractional composition; microstructure; Colloidal Instability Index $\left(I_{\mathrm{c}}\right)$.

\begin{tabular}{|ll|}
\hline Nomenclature \\
SARA & Saturates, Aromatics, Resins, Asphaltenes \\
$K F$ & Karl Fischer titration \\
TLC-FID & Thin-Layer Chromatography with Flame-Ionization Detection \\
$I_{c}$ & Colloidal Instability Index \\
\hline
\end{tabular}

\section{Introduction}

Bitumen in its emulsified form is used in a wide range of applications for construction, maintenance and preventive maintenance treatments. Development of technologies utilizing asphalt emulsions are a product of cooperation among emulsion manufacturers, equipment manufacturers and contracting companies [9]. Emulsion chemistry is responsible for immediate coating and subsequent cohesive strength development. Residual binder properties determine long term performance [9]. Three chemical components of emulsified bitumen, i.e. bitumen, water and emulsifier, joined together by the chemical influence of a colloid mill. They are the most necessary ingredients in the chemistry and related production of paving asphalt emulsions. The one physical-chemical property of paving asphalts that most influences the preparation of stable emulsions is the degree to which the asphaltene fraction is peptized by the maltene fraction into stable, colloidally and uniformly dispersed micelles [11].

Bitumen is a complex chemical mixture which consists of saturates, aromatics, resins and asphaltenes that can modify the stability of the bitumen emulsion [1-3]. Bitumen emulsion is applied on the road at lower temperatures than pure bitumen or polymer modified bitumen so it must be metastable. The contact between the bitumen droplets and the mineral surfaces can induce the emulsion breakdown on the aggregates [4-7].

Boulangé and Sterczynski developed new physical-chemical methods to characterise the aggregates, the bitumen and the bitumen emulsion surfaces. Also they compared the properties of the new sustainable emulsifiers which are currently used in the road industry and explained the role of the bitumen/aggregate interactions in the bitumen emulsion breakdown. Using

Corresponding author: Migle Paliukaite. E-mail address: migle.paliukaite@vgtu.lt

http://dx.doi.org/10.3846/enviro.2014.168

(C) 2014 The Authors. Published by VGTU Press. This is an open-access article distributed under the terms of the Creative Commons Attribution License, which permits unrestricted use, distribution, and reproduction in any medium, provided the original author and source are credited. 
the Drop Shape Analysis System surface tension of complex liquids such as bitumen was determined [8]. The Karl Fischer (KF) titration method for quantification of water has been successfully applied to asphalt binder. A KF titration method for quantifying water in bitumen and bitumen emulsions has been developed that it's accurate, quick, and highly sensitive [12].

Modified bitumen emulsion is a new kind of binder used in road surfaces, which has the advantages for both modified bitumen and bitumen emulsion. Using modified bitumen some properties will be improved, such as the thermal stability, high and low temperature performance, durability, as well as adhesive properties with aggregates and better resistance to cracking. Analysis of the relationship between the components and properties of bitumen showed that the change of components caused by SBS latex was beneficial to the properties of bitumen. The Colloidal Index $\left(I_{\mathrm{c}}\right)$ showed that SBS latex also made the colloidal system more stable [10].

\subsection{Bitumen fractional composition and microstructure}

There is an application of bitumen production used in cationic emulsions in Belarus. Oil refineries have been producing only oxidized bitumen. Several years ago they also started to produce special compounded bitumen. The results of bitumen fractional composition is determined by Thin-Layer Chromatography with Flame-Ionization Detection (TLC-FID) and bitumen rheological properties influence on cationic emulsions are presented.

To obtain cationic emulsified bitumen, used in the road construction technologies, domestic bitumen is generally used in the Republic of Belarus. Petroleum refineries produce bitumen by oxidation of petroleum residue using air oxygen, and only recently they have started producing special compounded bitumen. The process of compounding is applied to produce commercial bitumen from several oxidized components with various degree of oxidation: from oxidized and unoxidized components. Mixing two-three components in various ratios it is possible to obtain a great number of commercial bitumen grades.

Bitumen structure depending on chemical composition, properties and molecule constitution is featured by diversity of the molecular structures that may considerable influence on material properties. Fig. 1 shows the specimen surfaces of bitumen BD 90/130 obtained by the method of oxidation and compounding. On a basis of their analyses a conclusion can be drawn that the structure of compounded bitumen significantly differs from oxidized one, despite the fact that the same raw components make up their basis. Therefore, oxidized bitumen is featured by polydisperse structure while compounded bitumen shows monodisperse structure [13] that produces positive effect on the structural stability of the latter. Physicalchemical properties of compounded bitumen are shown in Table 1.

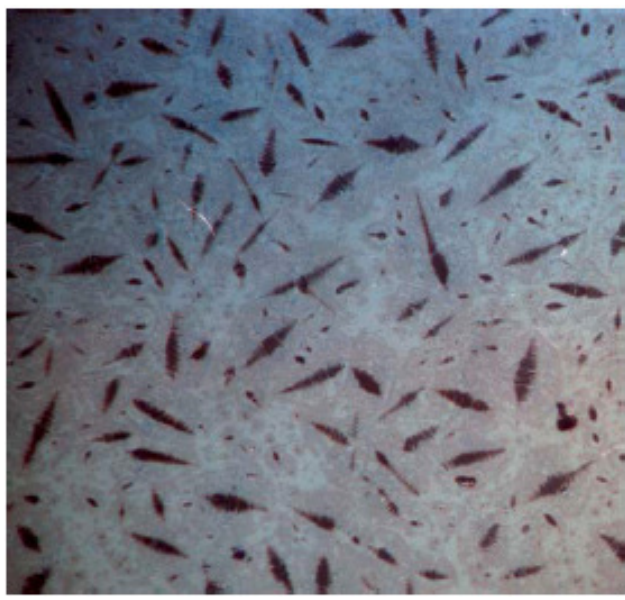

a)

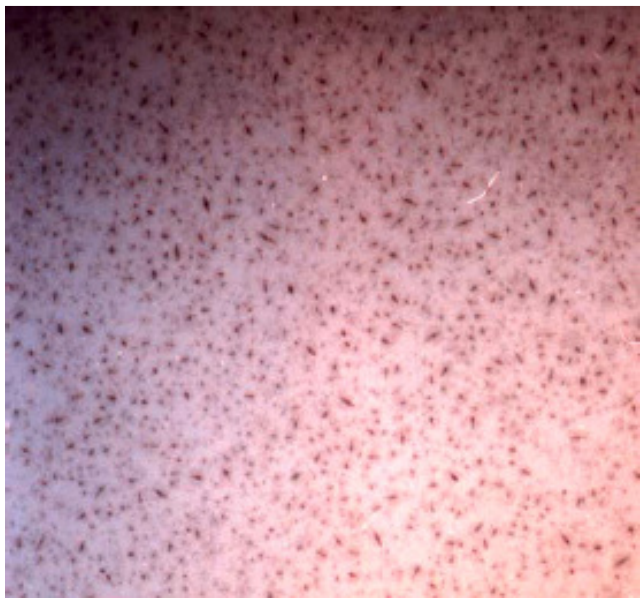

b)

Fig. 1. Specimen surfaces of bitumen BD 90/130 obtained by the method of oxidation (a) and compounding (b); optical microscopy (magnification $\times 200$ )

Table 1. Physical-chemical properties of compounded bitumen

\begin{tabular}{|c|c|c|c|c|}
\hline Index & \multirow[t]{2}{*}{ Norm as per STB 1062} & \multicolumn{3}{|c|}{ Batch number (BD 90/130) } \\
\hline & & 1 & 2 & 3 \\
\hline Softening temperature, ${ }^{\circ} \mathrm{C}$ & $\geq 43$ & 44 & 44 & 45 \\
\hline Extensibility, $\mathrm{cm}$, at $25^{\circ} \mathrm{C}$ & $\geq 65$ & over 100 & over 100 & over 100 \\
\hline at $0{ }^{\circ} \mathrm{C}$ & $\geq 4.0$ & 8.4 & 7.0 & 5.3 \\
\hline Penetration, $0.1 \mathrm{~mm}$, at $25^{\circ} \mathrm{C}$ & $91-130$ & 122 & 114 & 98 \\
\hline at $0{ }^{\circ} \mathrm{C}$ & $\geq 28$ & 56 & 41 & 39 \\
\hline Brittleness temperature, ${ }^{\circ} \mathrm{C}$ & $\leq-17$ & -20 & -19 & -19 \\
\hline $\begin{array}{l}\text { Batch composition, } \% \text { mass: } \\
\text { asphaltenes }\end{array}$ & $19-21$ & 18.5 & 18.0 & 18.5 \\
\hline resins & $32-34$ & 18.5 & 17.0 & 18.5 \\
\hline oils & $45-49$ & 63.0 & 65.0 & 63.0 \\
\hline paraffin & $\leq 3.0$ & 2.6 & 2.8 & 2.7 \\
\hline
\end{tabular}


Analysis of the presented results reveals that compounded bitumen considerably exceeds the requirements of the referenced normative document. This bitumen possesses, for example, higher extensibility and penetration at the temperature of $0^{\circ} \mathrm{C}$ as well as lower temperature of brittleness that is indicative of enhanced low-temperature properties. Moreover, judging by the batch composition, this bitumen is much less disposed to ageing which may be presented in simplified terms as the process of transformation of aromatic polycyclic hydrocarbons into resins, resins into asphaltenes, and the latter - into hard carbenes and carboides. By using thin-layer chromatography it was determined that the content of aromatic hydrocarbons increases in compounded bitumen which presupposes better compatibility with the materials of acidic rocks in the composition of asphaltic concrete as well [14].

The properties of bitumen as dispersive systems depend on the chemical composition of dispersion medium and dispersed phase. In this connection Kalbanovskaya has identified two main and one intermediate structural type for bitumen: Gel, Sol and Sol-Gel [15].

Bitumen of the first type (Gel) contains over $25 \%$ (by mass) of asphaltenes and less than $24 \%$ of resins. Bitumen of the second type (Sol) contains up to $18 \%$ of asphaltenes and over $36 \%$ of resins. Bitumen of the third type (Sol-Gel) contains an average content of asphaltenes $-21-23 \%$, resins $30-34 \%$. Bitumen of the third type is featured by the structure that includes elements of both structures.

Each type of bitumen is characterized by the chemical composition and molecular structure that have influence to rheological properties:

- type I has a high viscosity which at attaining the value of ultimate shear stress after mechanical impact decreases sharply (down to 6-12\%) but after relieving the stress it would quickly restore practically back to the initial value;

- type II - viscosity depends little on shear rate (after impact it remains at $90-96 \%$ of the initial value), however, viscosity drop occurs right after application of shear stress and after its relieving viscosity would not actually restore;

- type III - after application of shear stress, viscosity decreases by $40-65 \%$ and after stress relieving it would restore but not completely (about 90\%).

Bitumen meeting the requirements of the normative documents, even within one grade, may be referred to different rheological types and correspondingly may differently behave in the process of emulsification. Table 2 shows physicalchemical characteristics of BD 90/130 bitumen produced at the enterprises of the Republic of Belarus and used for road construction.

Table 2. Physical-chemical indices of bitumen

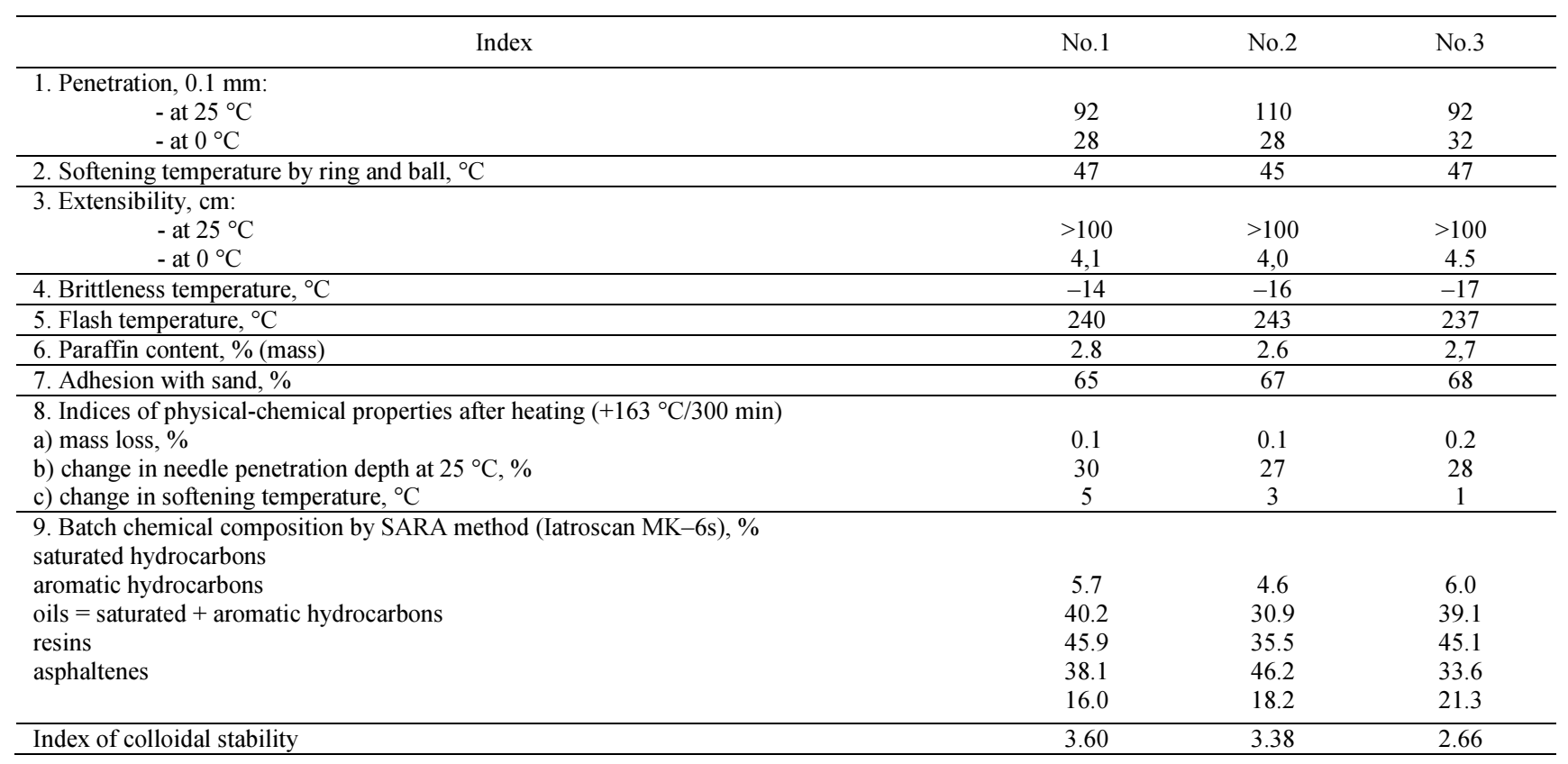

\subsection{Bitumen Colloidal Instability Index (Ic)}

Index of colloidal stability is determined by the following relationship:

$$
I_{\text {coll.stab. }}=\frac{\text { aromatics }+ \text { resin } s}{\text { asphaltenes } .+ \text { saturates }}
$$

This index is used to characterized bitumen structural characteristics and is called index of bitumen dispersivity (D) [16]. At high content of asphaltenes and saturated hydrocarbons the index of bitumen dispersivity decreases, asphaltenes are 
poorly dispersed, and the colloidal system becomes more unstable.

It is evident from the data shown in Table 2 that the batch chemical composition of bitumen No. 1 and No. 2 are referred to type II, whereas bitumen No. 3 - is referred to structural type III according to the classification developed by Kalbanovskaya.

From the studies of the batch composition of bitumen used in the road construction companies of the Republic of Belarus it has shown that bitumen is most frequently referred to type III, type II - III or type II.

In order to determine the effect of bitumen chemical composition and its rheological type on the properties of emulsified bitumen fast and slow decomposing cationic road emulsions have been produced using bitumen of different types and with different index of colloidal stability.

It has been established that bitumen referred to structural type III is better emulsified, and emulsions meeting the requirements of the normative document can be made with lesser consumption of emulsifier. More emulsifier is needed to produce emulsion from bitumen of type II. The data obtained are consistent [17], i.e. bitumen referred to types I and III is the most suitable to prepare emulsified bitumen since viscosity of type II bitumen changes little at application of shear stress and the process of its emulsification is more complicated.

Fast-decomposing bitumen emulsions are widely used for surface treatment durability of which can be evaluated by adhesion of bitumen with stone material (method of boiling) and by decrepitation stability of bitumen film at impact (PS-2 instrument at $0{ }^{\circ} \mathrm{C}$ ). The data obtained are shown in Figs 2, 3. It is evident from the figures that surface treatments made with the use of emulsions prepared from structural-rheological type III bitumen are featured by higher adhesion and decrepitation stability at impact at $0{ }^{\circ} \mathrm{C}$. Moreover, it has been proven that not only bitumen but also emulsifier used as well exerts influence on this index (Fig. 3). Slow-decomposing emulsified bitumen has been used in the composition of cold cast bituminous concrete mixtures (variety A), slurry seal, physical-mechanical characteristics of which are provided in Table 3 .

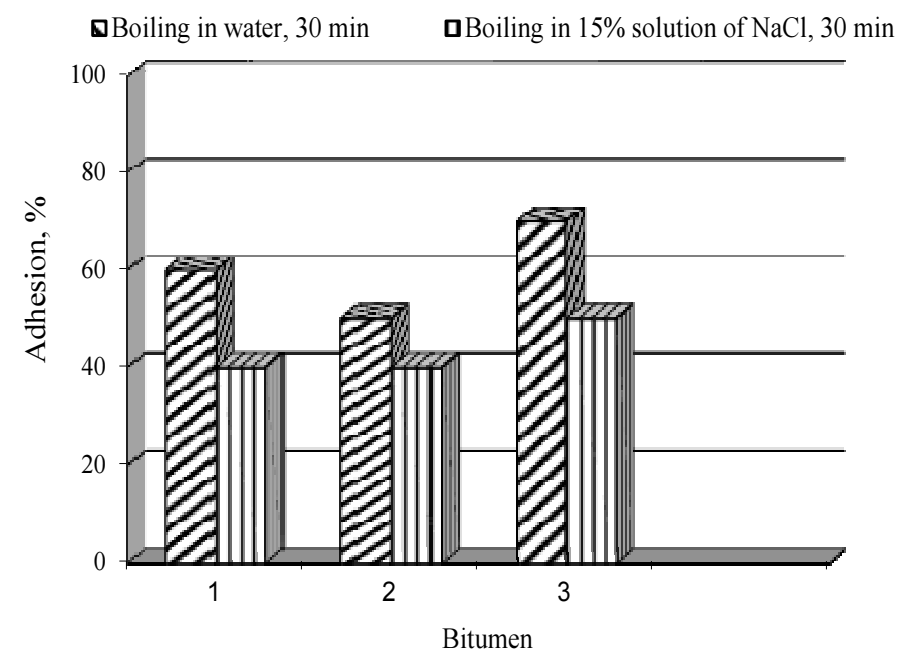

Fig. 2. Adhesion of emulsified bitumen with crushed granite depending on bitumen type

口Dinoram SL 口Redicote

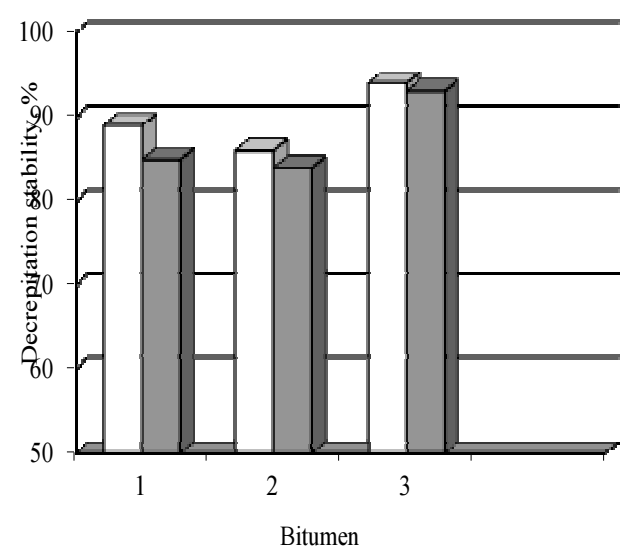

Fig. 3. Effect of bitumen type on decrepitation stability as measured by PS-2 instrumentat $0{ }^{\circ} \mathrm{C}$ 
Table 3. Physical-mechanical characteristics of cold cast bituminous concrete mixtures

\begin{tabular}{|c|c|c|c|c|c|c|c|c|}
\hline \multirow{3}{*}{$\begin{array}{c}\text { Initial } \\
\text { bitumen }\end{array}$} & \multirow{3}{*}{$\begin{array}{l}\text { Emulsion grade, } \\
\text { amount of } \\
\text { emulsion, } \%\end{array}$} & \multicolumn{7}{|c|}{ Physical-mechanical properties of the mixtures } \\
\hline & & \multirow{2}{*}{$\begin{array}{c}\text { Deformation } \\
\text { property at } \\
\text { wheel load,\% }\end{array}$} & \multirow{2}{*}{$\begin{array}{l}\text { Quartz } \\
\text { sand } \\
\text { adhesion, } \\
\mathrm{kg} / \mathrm{m} 2\end{array}$} & \multicolumn{2}{|c|}{ Abrasive wear, $\mathrm{g} / \mathrm{m} 2$} & \multicolumn{3}{|c|}{$\begin{array}{l}\text { Attainment of torque moment with } \\
\text { time, } \mathrm{kg} / \mathrm{cm} 2\end{array}$} \\
\hline & & & & $\begin{array}{c}1 \text { hour of } \\
\text { water } \\
\text { saturation }\end{array}$ & $\begin{array}{c}6 \text { days of } \\
\text { water } \\
\text { saturation }\end{array}$ & 0.5 hour & 1.0 hour & 2.0 hours \\
\hline \multirow{2}{*}{$\begin{array}{l}\text { Bitumen No. } \\
1 \text { P25 - } 92 \\
\text { mm-1 }\end{array}$} & EBK-M-60 - 15 & 9.1 & 272.4 & 12.0 & 18.6 & 8 & 12 & 21 \\
\hline & EBK-M-60 - 13 & 12.4 & 314.0 & 78.30 & 98.4 & 6 & 15 & 23 \\
\hline \multirow{2}{*}{$\begin{array}{l}\text { Bitumen No. } \\
2 \text { P25 - } 110 \\
\text { mm-1 }\end{array}$} & EBK-M-60 -15 & 12.0 & 263.7 & 11.9 & 13.5 & 10 & 18 & 21 \\
\hline & EBK-M-60 - 13 & 13.2 & 358.9 & 101.2 & 120.0 & 9 & 15 & 23 \\
\hline \multirow{2}{*}{$\begin{array}{l}\text { Bitumen No. } \\
3 \text { P25 - } 92 \\
\text { mm-1 }\end{array}$} & EBK-M-60 - 15 & 18.4 & 278.0 & 19.8 & 64.2 & 15 & 20 & 28 \\
\hline & EBK-M-60 - 13 & 17.5 & 372.0 & 94.6 & 124.4 & 14 & 16 & 26 \\
\hline \multicolumn{2}{|c|}{$\begin{array}{l}\text { Norm as per RD } 0219.1 .09-99 \text { for } \\
\text { the mixtures of variety A }\end{array}$} & - & $\begin{array}{l}\text { not over } \\
750\end{array}$ & not over 800 & not over 530 & not less 12 & not less 20 & not less 26 \\
\hline
\end{tabular}

It is seen from the data presented in Table 3 that the mixtures obtained with the use of emulsified bitumen based on bitumen of structural type III are formed faster. For instance, traffic on the road from cold cast mixtures with the use of emulsion based on bitumen No. 3 can be allowed in one hour, whereas with the use of emulsion based on bitumen of type II - in two hours. It should be noted that bitumen No. 3 is compounded and better results of resumed traffic have been ensured with its use. This has been confirmed in practice by road surfacing with application of Slurry seal technology on the Belarusian roads, i.e. the use of compounded bitumen has made it possible to attain minimum time of road surface formation and resumption of traffic on the laid coating.

Thus, it has been shown that to obtain emulsified bitumen and its rational use in the road construction it is more preferable to make use bitumen of structural-rheological type III.

Apart from the structural-rheological type of bitumen a value of the colloidal stability index should be taken into consideration as well. The values of $I_{\mathrm{c}}$ in bitumen produced by the Belarusian enterprises are provided in Figure 4 .

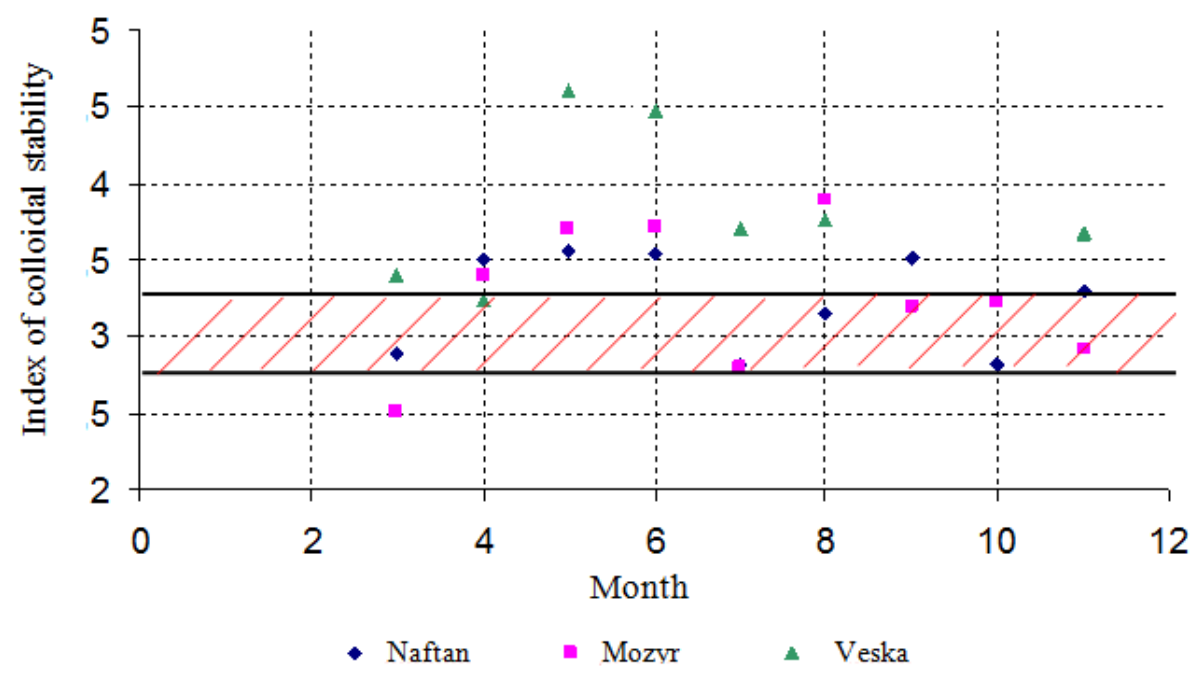

Fig. 4. Index of colloidal stability of road bitumen produced by the Belarusian enterprises in 2008

It is understood from the data provided that $I_{\mathrm{c}}$ values ranging from 2.75 to 3.75 are typical of bitumen. On the basis of undertaken investigations aimed for obtaining bitumen emulsions from bitumen of different index of colloidal stability, studies of physical-mechanical properties of fast- and slow-decomposing bitumen emulsions as well as properties of emulsion-mineral mixtures it has been ascertained that:

- bitumen with colloidal instability ranging from 2.75 to 3.2 is recommended to be used for preparation of cationic

- bitumen emulsions to make protecting layers from cold cast asphalt-concrete mixtures and for road surface treatment;

- bitumen with colloidal instability less than 2.75 is recommended to be used for preparation of cationic bitumen emulsions to make priming of the coatings and for rehabilitation of the asphalt-concrete coatings (as impregnating emulsions);

- bitumen with colloidal instability over 3.2 is recommended to be used for preparation of cationic bitumen emulsions to make constructional layers of the road coatings from emulsion-mineral mixtures with the use of adhesive admixtures. 
If there is a need to use bitumen with colloidal instability less than 2.75 to prepare fast-decomposing bitumen emulsions to carry out road surface treatment it is recommended to increase emulsifier consumption and to add adhesive admixtures.

If there is need to use bitumen with colloidal instability over 3.2 to prepare slow-decomposing bitumen emulsions to make protecting layers from cold cast asphalt-concrete mixtures it is recommended to use phosphoric acid and adhesive admixtures.

When fluxing additives are used to dilute bitumen it is necessary to take into consideration the effect produced by such additives on changes in the bitumen component composition.

A final conclusion on expediency of bitumen use to prepare a specific grade of emulsified bitumen and its application for this or that technology can be drawn after a comprehensive study in a specialized laboratory.

\section{Conclusion}

According to the experimental research and depending on the colloidal stability index there are three types of bitumen. Bitumen with the colloidal stability index lower than 2.75 is recommended to be applied for production of road emulsions for asphalt pavement priming and rehabilitation. Bitumen with the colloidal stability index from 2.75 to 3.2 is recommended to be applied for production of road cationic emulsions for covering layers application (Slurry seal) and surface dressing. Bitumen with the colloidal stability index higher than 3.2 is recommended to be applied for production of road emulsions with adhesion agent adding.

It was established that using bitumen emulsions with compounded bitumen the maximal speed of formation of a road surfacing from cold emulsion mixtures is reached. The results of practical application of bitumen emulsions with compounded bitumen for Slurry seal in road building in Belarus are presented.

\section{References}

[1] Redelius, P. G. 2006. Road Mater, Pavement Design 7: 143 http://dx.doi.org/10.1080/14680629.2006.9690062

[2] Jäger, A.; Lackner, R. C. 2004. Eisenmenger-Sittner and R. Blab, Road Mater. Pavement Design 5: 9. http://dx.doi.org/10.1080/14680629.2004.9689985

[3] Khristov, K.; Taylor, S. D.; Czarnecki, J.; Masliyah, J. 2000. Colloids Surfaces A 174: 183. http://dx.doi.org/10.1016/S0927-7757(00)00510-0

[4] Liu, J.; Xu, Z.; Masliyah, J. 2005. Colloids Surfaces A 260: 217. http://dx.doi.org/10.1016/j.colsurfa.2005.03.026

[5] Salou, M.; Siffert, B.; Jada, A. 1998. Colloids Surfaces A 14: 9. http://dx.doi.org/10.1016/S0927-7757(98)00406-3

[6] Zhou, Z. A.; Xu, Z.; Masliyah, J. H.; Czarnecki, J. 1999. Colloids Surfaces A 148: 199. http://dx.doi.org/10.1016/S0927-7757(98)00677-3

[7] Rodriguez-Valverde, M. A.; Cabrerizo-Vilchez, M. A.; Paez-Duenas, A.; Hidalgo-Alvarez, R. 2003. Colloids Surfaces A 222: 233. http://dx.doi.org/10.1016/S0927-7757(03)00228-0

[8] Boulangé, L.; Sterczynski, F. 2012. Study of Interfacial Interactions between Bitumen and Various Aggregates Used in Road Construction, Journal of Adhesion Science and Technology 26: 163-173.

[9] Asphalt Emulsion Technology. 2006. Transportation Research Circulare E-C102.

[10] Cai, H. M.; Wang, T.; J. Y. Zhang, J. Y.; Zhang, Y. Z. 2010. Preparation of an SBS Latex-Modified Bitumen Emulsion and Performance Assessment, Petroleum Science and Technology 28: 987-996. http://dx.doi.org/10.1080/10916460902939436

[11] Dybaiski, J. N. 1976. The Chemistry of Asphalt Emulsions, in Fifty-Fifth Annual Meeting Transportation Research Board January 1976.

[12] Boysen, R. B.; Boysen, R. B.; Planche, J. P. 2014. Quantification of Water in Asphalt by Karl Fischer Titration and its Application to Emulsion Recovery, in TRB 2014 Annual Meeting.

[13] Tkachev, S. M. 2006. Hierarchical structure of petroleum residues and bitumen. Herald of the Polotsk State University, Fundamental science (4): 150156.

[14] Tsyro, L. V.; Andreyeva, L. N.; Ungher, F. G. 2007. Some causes of bitumen composition ageing, in Materials of III All-Russian Scientific Production Conference on the problems of production and application of bitumen materials. Perm, pp. 98-99.

[15] Kolbanovskaya, A. S.; Mikhailov, V. V. 1973. Road bitumen. - M.: Transport, 1973.

[16] Ghun, R. B. 1973. Petroleum bitumen - M.: Chemistry, 1973.

[17] Bitumen in road construction: Papers of the International Conference, M., April 19-22, 2005, pp. 58-62. 